\title{
Yaşlılarda Düşme Riskinin Belirlenmesi İçin Yürüyüş Esnasında Kayıt Edilen İvmelenme Sinyallerinin Zaman Domeni Özelliklerinin Degerlendirilmesi
}

\author{
Sabri Altunkaya ${ }^{1 *}$ \\ 1* Necmettin Erbakan Üniversitesi, Mühendislik-Mimarlık Fakültesi, Elektrik Elektronik Mühendisliği, Konya, Türkiye, (ORCID: 0000-0002-0853-0095), \\ saltunkaya@konya.edu.tr
}

(İlk Geliş Tarihi 5 Haziran 2020 ve Kabul Tarihi 16 Ekim 2020)

(DOI: $10.31590 /$ ejosat.748156)

ATIF/REFERENCE: Altunkaya, S., (2020). Yaşlılarda Düşme Riskinin Belirlenmesi İçin Yürüyüş Esnasında Kayıt Edilen İvmelenme Sinyallerinin Zaman Domeni Özelliklerinin Degerlendirilmesi. Avrupa Bilim ve Teknoloji Dergisi, (20), $367-373$.

Öz

Yaşlanmayla birlikte vücutta meydana gelen anatomik ve fizyolojik değişimlerin bir sonucu olarak yaşlı bireylerde düşme bir sağlık problemi olarak karşımıza çıkmaktadır. Dünya sağlık örgütüne göre düşme yaşlılarda görülen en önemli sağlık problemidir. Düşmenin yaşlının fiziksel olarak yaralanması ve düşme korkusunun getirdiği psikolojik etkinin yanında hastaya, aileye ve topluma ekonomik olarak etkileri vardır. Dünyada ve ülkemizde sağlı alanında meydana gelen gelişmelerle beraber bireylerin yaşam süresinin hızla artmasıyla bu etki daha da belirgin hale gelecektir. Ancak yaşlılarda düşmenin önlenmesi ile bu olumsuz etkiler azaltılabilir. Yaşlılarda düşmenin etkilerini azaltmak için etkili yöntem düşmenin önceden tahmin edilmesi ve gerekli önlemlerin alınmasıdır. Düşmenin önceden tahmin edilebilmesi için yaşlılarda rutin kontrollerinde dengenin değerlendirilmesi gerekmektedir. Bunun için birinci basamak sağlık kuruluşlarında kullanılabilecek basit, ucuz ve güvenilir bir denge değerlendirme metodunun geliştirilmesi önemlidir. Duruş ve hareket sınıflandırması, enerji harcama tahmini, anlık düşme tespiti ve denge kontrolü gibi fiziksel aktivite izleme ve değerlendirme araştırmalarında sıklıkla kullanılan ivmeölçerler yaşlılarda düşme riskinin değerlendirmesi için rahatlıkla kullanılabilir. Bu çalışmada yaşları 65 ile 87 arasında değişen 71 yaşlıdan (38 kontrol 35 düşme riski olan) düz zeminde yürüme esnasında kayıt edilen bir dakikalık üç eksen ivmelenme sinyalleri kullanılarak yaşlılarda düşme riskini tanımlayıcı parametreler bulunmaya çalışılmıştır. Önce kayıt edilen ivmelenme sinyalinden yer çekiminden kaynaklanan bileşen çıkarılmış, daha sonra $0.5 \mathrm{~Hz}-5 \mathrm{~Hz}$ bant geçiren filtreyle yüksek frekanslı gürültüler temizlenmiştir. Gürültü temizleme işleminden sonra bir dakikalık kayıtlar adımlara bölünmüş ve normalize edilerek özellik çıkarma işlemine geçilmiştir. Özellik çıkarma aşamasında literatürden farklı olarak daha önce yaşlılarda düşme riski için kullanılmayan zaman-domeni özellikleri de değerlendirilmeye alınmıştır. Elde edilen özellikler bağımsız-örneklem t-testi kullanılarak \%99 güvenirlik seviyesinde karşılaştırılmıştır. Sonuç olarak literatürde anlamlı olarak farklı olduğu daha önceki çalışmalarda belirtilen kadans, adım süresi, çift adım süresi özellikleri benzer şekilde bizim çalışmamızda da kontrol ile düşen grupları arasında anlamlı farklılık göstermiştir. Ayrıca literatürde daha önce düşme riskinin değerlendirilmesi için yapılan çalışmalarda kullanılmayan çarpıklık, çeyrekler arası aralık, ortalama mutlak sapma ve dinamik zaman atlama özelliklerinde de anlamlı farklılık olduğu görülmüştür. Çalışmamızda ivmelenme sinyallerinden elde edilebilecek bütün zaman domeni özellikleri düşme riskinin belirlenmesi için değerlendirilmiştir. Sonuç olarak literatürde daha önce düşme riski için kullanılmayan dört yeni zaman domeni özelliğinin düşme riskini belirlemede kullanılabileceği ortaya konmuştur.

Anahtar Kelimeler: İvmelenme sinyali, Zaman-domeni özellikler, Yaşlilarda düşme.

\footnotetext{
*Sorumlu Yazar: saltunkaya@konya.edu.tr
} 


\title{
Evaluation Of Time Domain Features Of The Acceleration Signals Recorded During The Walk To Determine The Risk Of Falling In The Elderly
}

\begin{abstract}
Fall in elderly is a health problem as a result of the anatomical and physiological changes in the body with aging. According to the world health organization, falling is the most important health problem in the elderly. In addition to physical injury and the psychological effects of fear of falling in elderly, the fall also has economic effects on the patient and society. With the developments of health system in the world, this effect will become more evident with the rapid increase in the life span of individuals. However, these negative effects can be reduced by preventing falls in the elderly. The effective method to reduce the fall in the elderly is to predict the fall and take the necessary prevents. In order to predict the fall, balance of elderly should be evaluated in routine controls. For this, it is important to develop a simple, cheap and reliable balance assessment method that can be used in primary health care centers. Accelerometers, which are frequently used in physical activity monitoring and evaluations such as posture and movement classification, energy expenditure estimation, instantaneous fall detection can be easily used for the assessment of fall risk in the elderly. In this study, it was aimed to find out the parameters that define the risk of falling in the elderly by using one-minute three-axis acceleration signals recorded during walking on flat ground from 71 elderly (38 control 35 with risk of falling) between 65 and 87 years of age. First, the component from gravity was removed from the recorded acceleration signal, then high frequency noises were removed with a filter at $0.5 \mathrm{~Hz}-5 \mathrm{~Hz}$. After the noise removal process, recordings were divided into steps and normalized and feature extraction process was started. Unlike the literature, time-domain features that were not used for the risk of falling in the elderly were also evaluated. The properties were compared statically at $99 \%$ reliability level. As a result, the cadence, stride duration, double stride duration, which were found to be significantly different in the literature, showed a significant difference between control and falling groups in our study too. In addition, it was found that there is a significant difference in skewness, interquartile range, average absolute deviation and dynamic time-wrapping that were not used in the previous studies to evaluate the risk of falling. In our study, all time domain properties that can be obtained from acceleration signals were evaluated to determine the risk of falling. As a result, it has been demonstrated that four new time domain features not previously used for assessment of falling risk in the literature can be used to determine the risk of falling.
\end{abstract}

Keywords: Acceleration signal, Time-domain features, Fall in the elderly.

\section{Giriş}

Düşme genellikle, mobilya, duvar veya diğer nesnelere oturmak veya yaslanmak amacıyla yapılan kasıtlı değişikliklerin dışında, zemine veya mevcut bulunduğunuz seviyeden daha alt bir seviyeye istemsiz geçmek olarak tanımlanır. 65 yaş ve üzerindeki insanların yaklaşık \%28-35'i her yıl düşer ve bu oran 70 yaşın üzerindekiler için \% 32-42'ye yükselir. Düşmeler ve buna bağlı yaralanmalar, genellikle tıbbi müdahale gerektiren büyük halk sağlığı sorunlarıdır. 65 yaş ve üstünde meydana gelen düşmelerin \%50'den fazlası hastanede bakım gerektirir. Ĕger yaşlıda düşme sonucu kalça kırığı meydana geldi ise bu vakaların \%20'si ölümle sonuçlanır. Ek olarak, düşmeler, günlük aktivitelerde daha fazla kısıtlamaya yol açacak olan bağımlılık, özerklik kaybı, immobilizasyon ve depresyon içeren bazı düşme sonrası sendromlarla sonuçlanabilir. Dünyadaki birçok ülkede yaşam süresindeki artma nedeniyle yaşlıların sayısı gittikçe artmaktadır. Dünya genelinde 60 yaş üstü insan sayısı diğer tüm gruplardan hızlı büyümektedir. 2006'da 688 milyon olan bu sayının 2050 de 2 milyar olacağı tahmin edilmektedir. Yaşlı nüfusundaki bu artış hızıyla birlikte düşme vakaları da artacaktır. Yakın gelecekte önleyici tedbirler alınmazsa, düşmelerden kaynaklanan yaralanma sayısının 2030 yılında \%100 daha fazla olacağı öngörülmektedir. Fiziki yaralanmaların dişında yaşlılarda düşme korkusunun oluşması ile birlikte, düşmenin sosyal yalıtım, hayat kalitesinde düşme ve hareketlerde azalma gibi endişe verici psikolojik sonuçları vardır. Ayrıca düşme sonrası yaralanmaların tedavisi ve hastaya evde bakım sürecinde yakınının iş gücü kaybı gibi nedenlerden düşmenin oldukça büyük bir ekonomik etkisi de söz konusudur. Düşmenin sağlık hizmetlerine etkileri ve ekonomik maliyetleri tüm dünyada önemli ölçüde artmaktadır. (WHO 2007).
Sonuç olarak fiziksel, psikolojik ve ekonomik etkileri oldukça ciddi olan yaşlılarda düşmenin önlenmesi hem toplum hem birey için oldukça önemlidir. Etkili bir önleme programı ilk olarak düşme riski bulunan yaşlının belirlenmesi ile başlar ve uygun olan önleme tedbirlerinin alınması ile devam eder (Castellini, Gianola ve ark. 2019, Wu, Lee ve ark. 2019). Bunun için yıllık kontrollerde yaşlıya önceki yıl düşüp düşmedikleri, kaç kere düştükleri, düştüğünde yaralanma olup olmadığı vb. sorulardan herhangi birine evet cevabı verildiğinde ise yaşlının denge değerlendirilmesinin yapılması önerilmektedir (Moncada ve Mire 2017). Hatta denge ile ilgili sorunu olmasa dahi 65 üstü bireylerin yıllık değil rutin kontrollerinde denge ve yürüme açısından değerlendirilmesiyle 65 yaş üstü bireylerde olan denge kaybı ve düşme riskinin erken saptanabileceği ve rehabilitasyon uygulamalarının zamanında başlamasına ve düşmenin önlenmesine olanak sağlayacağı düşünülmektedir (Koyuncu, Tuna ve ark. 2017). Dolayısıyla 65 yaş üstü bireylerin birinci basamak sağlık merkezlerinde rutin kontrollerinde denge ve düşme değerlendirilmesinden geçmelerinin etkin bir düşme kontrolü sağlayacağı açıktır.

Denge statik ve dinamik denge olmak üzere iki alt bölümde incelenir. Statik denge değerlendirmesinde kullanılan tüm testlerin ortak dezavantaj1, günlük yaşam aktivitelerinin çoğunda kullanılan adaptif postural yanıtları değerlendirmekte yetersiz olmalarıdır(Balaban, Nacır ve ark. 2009). Dolayısıyla doğru bir düşme riski değerlendirilmesi için dinamik dengenin ölçülmesi gerekmektedir. Dinamik dengenin değerlendirilmesi klinik ortamda uygulanabilen anket ve basit testlerden, bilgisayar kontrollü karmaşık cihazlarla yapılan ileri ölçümlere kadar farklı şekillerde yapılabilir (Balaban, Nacır ve ark. 2009, Koyuncu, Tuna ve ark. 2017). Düşme risk değerlendirmesi için kullanılan anket ve basit fizyolojik testler kesin bir nesnel yöntem 
olmadıkları gibi sübjektif ve niteldir (Najafi, Aminian ve ark. 2002, Howcroft, Kofman ve ark. 2013, Sun ve Huang 2019). Bir takım sensörler kullanan bilgisayar kontrollü gelişmiş cihazların ise birinci basamak sağlık kuruluşlarında kullanılması mekân, uzman gereksinimi, test süresi ve maliyet gibi dezavantajları nedeniyle kullanımı imkânsızdır (Balaban, Nacır ve ark. 2009, Yang ve Hsu 2010, Howcroft, Kofman ve ark. 2013). Bu sebeplerden yaşlilarda düşmenin önceden tespit edilerek önlenmesi için ucuz, kullanımı kolay, objektif ve nicel bir yöntemin gerekli olduğu anlaşılmaktadır.

Fiziksel aktivitenin ölçülmesi ve değerlendirilmesinde, ivmeölçerler giyilebilir sağlık cihazları için kullanışlı ve pratik sensörler olarak kabul görmüşlerdir (Mathie, Coster ve ark. 2004). Literatürde ivmeölçerler duruş ve hareket sınıflandırması, enerji harcama tahmini, anlık düşme tespiti ve denge kontrolü gibi fiziksel aktivite izleme ve değerlendirme araştırmalarında kullanılmaktadır (Yang ve Hsu 2010). Son yıllarda yaşlılarda düşmenin erken tespiti içinde kullanılmaya başlanmıştır. $\mathrm{Bu}$ amaçla yapılan çalışmalarda özellikle yürüme esnasında ivmeölçerlerden kayıt edilen ivmelenme sinyallerinden zaman, frekans ve zaman-frekansa bağımlı özellikler elde edilmiştir. Elde edilen özellikler ya istatiksel olarak değerlendirilerek gruplar arasında fark olup olmadığına bakılmış ya da bir sınıflama modeli oluşturularak sınıflandırılmıştır (Howcroft, Kofman ve ark. 2013). Bu çalışmalarda zaman domeni özellikleri olarak ortalama adım süresi, ortalama çift adım süresi, adım düzenliliği, çift adım düzenliliği, adım simetrisi, harmonik oran, ivmelenme sinyalinin en büyük, en küçük, standart sapma ve ortalama değerleri kullanılmıştır (Weiss, Brozgol ve ark. 2013, Howcroft, Kofman ve ark. 2017, Howcroft, Kofman ve ark. 2017). Fakat zaman domeni sinyallerin değerlendirilmesinde kullanılabilecek başka özellikler de vardır (Pires ve ark. 2019). Bu çalışmada ivmelenme sinyali için kullanılabilecek bütün zaman domeni özelliklerini kapsayan ve aynı veri seti üzerinde bu özelliklerin hesaplanıp değerlendirilmesi amaçlanmıştır. $\mathrm{Bu}$ amaçla hem literatürde düşme risk değerlendirmesi için kullanılan zaman domeni özellikleri hem de litertürde yer almayan ancak ivmelenme sinyalleri için kullanılabilecek diğer zaman domeni özellikleri hesaplanmış ve istatistiksel olarak gruplar arasında farklılık olup olmadığı araştırılmıştır.

\section{Materyal ve Metot}

\subsection{Katılımcilar}

Uzun dönem hareket görüntüleme (Long Term Movement Monitoring Database) veri tabanı düşme riski, denge ve yürüyüş çalışmaları için 71 yaşlıdan kayıt edilen üç gün ve bir dakikalık 3D ivmelenme sinyallerinden oluşur (Goldberger, Amaral ve ark. 2000). Katılımcıların ortalama yaşı $78.36 \pm 4.71$ 'dır ve 65 ile 87 arasında değişmektedir. Üç günlük kayıtlar ev ortamında katılımcının ivmeölçer kemerini kendi kullanımı ile alınmıştır. Bir dakikalık kayıtlar katılımcıların kendi seçtikleri hızda, ivmeölçer yürüyüş kemeri ile birlikte laboratuvar ortamında yürümeleri esnasında alınmıştır. Katılımcılar önceki düşmeleriyle ilgili verdikleri rapora bağlı olarak 38 kişi kontrol ve 35 kişi düşen olarak sınıflandırılmıştır. Eğer katılımcı son bir yıl içerisinde 2 defa düştü ise düşen, düşmediyse kontrol olarak alınmıştır (Weiss, Brozgol ve ark. 2013). Bu çalışmada birinci basamak sağlık kuruluşlarında kullanılabilecek basit bir yöntem geliştirilmesi amaçlanmıştır. Dolayısıyla hem kısa zamanda değerlendirme elde edilmesi hem kayıt cihazının aktif kullanılması için veri tabanındaki bir dakikalık kayıtların amacımız için daha doğru olacağı görülmektedir. Bu yüzden analiz için bir dakikalık kayıtlar kullanılmıştır.

\section{2. Önişleme}

Ham ivmelenme sinyalleri dikey(V), mediyolateral (ML) ve ön-arka (anterior-posterior) (AP) olmak üzere üç eksende kayıt edilir. Ham sinyallere uygulanan ilk işlem istenmeyen ani değişimlerin etkisini azaltmak için 3 dereceli medyan filtre ile filtrelemektir. Kayıt edilen ham ivmelenme sinyalleri yerçekimi ve yürüyüş olmak üzere iki bileşenden oluşur. Bizim analiz için kullanacağımız bileşen yürüyüşten kaynaklanan ivmelenme sinyalidir. $\mathrm{Bu}$ iki bileşeni ayırabilmek için, ham ivmelenme sinyali ilk olarak $0.25 \mathrm{~Hz}$ alçak geçiren filtreyle filtrelenerek yerçekiminden kaynaklanan ivmelenme sinyali bulunur. Daha sonra yerçekiminden kaynaklanan ivmelenme sinyali ham ivmelenme sinyalinden çıkarıldığında vücut hareketlerinden yani yürüyüşten kaynaklanan bileşen elde edilmiş olur. Son olarak yürüyüşten kaynaklanan ivmelenme bileşeni $0.5 \mathrm{~Hz}-5 \mathrm{~Hz}$ bant geçiren filtreyle filtrelenerek yüksek frekanslı gürültüler atılır (Karantonis, Narayanan ve ark. 2006). Bu işlemler üç eksene ait ivmelenme sinyallerine de uygulanmıştır.

\subsection{Zaman Domeni Özellikleri}

Bu çalışmada yürüyüş analizinde yaygın olarak kullanılan zaman domeni özelliklerine ilave olarak bir takım istatistiksel yeni özellikler ilave edilmiştir. Bir kişiye ait özellikler hesaplanırken önce o kişiye ait ivmelenme sinyali adımlara bölünmüş, daha sonra her adım için elde edilen ivmelenme sinyali -1 ile 1 arasına normalize edilmiştir. Normalize edilen sinyalden aşağıda detaylarını açıkladığımız özellikler hesaplanmış ve her özelliğin ortalaması kişiye ait özellik olarak alınmıştır. Bu işlem üç ivmelenme ekseni için tekrarlanmıştır. Böylece her ivmelenme ekseni için 27 toplamda ise 81 özellik elde edilmiştir. Hesaplanan özellikler ve kısaltmaları aşağıda verilmiştir. Ayrıca sonuçlar verilirken her özelliğin sonuna kayıt edildiği ekseni göstermesi için eksenin kısaltması eklenmiştir.

1. Ortalama Adım Süresi (AdS): Ardışık iki minimum arası sürelerin ortalamasıdır.

2. Ortalama Çift Adım Süresi (çAdS): Ardışık iki adım süresini toplamının ortalamasidır.

3. Adım Düzenliliği (AdDz): İvmelenme sinyalinin ortalama adım süresi kadar kaydırılmasıyla elde edilen yeni sinyal ile arasındaki korelasyondur (Barden, Clermont ve ark. 2016).

4. Çift Adım Düzenliliği (çAdDz): İvmelenme sinyalinin ortalama çift adım süresi kadar kaydırılmasıyla elde edilen yeni sinyal ile arasındaki korelasyondur (Barden, Clermont ve ark. 2016).

5. Adım Simetrisi (AdSim): Adım düzenliliği ile çift adım düzenliliği arasındaki yüzde farkı ifade eder (Barden, Clermont ve ark. 2016). Aşağıdaki şekilde hesaplanır.

$$
A d \operatorname{Sim}=\frac{|A d D z-c ̧ A d D z|}{(A d D z+c ̧ A d D z) / 2} \cdot 100
$$

6. Kadans (Kdn): Dakikadaki adım sayısı olarak kişinin yürüme hızıdır.

7. Harmonik Oran (HR): Harmonik oran yürümenin düzgünlüğünün bir ölçüsüdür ve ivmelenme sinyali çift harmonikleri genlik toplamının tek harmonikleri genlik toplamına oranı olarak tanımlanır. (Bellanca, Lowry ve ark. 2013).

8. Ortalama (Ort): İvmelenme sinyal genliğinin ortalama değeridir. 
9. Ilk Yarı Ortalaması (ilkOrt): İvmelenme sinyal genliğinin adım başından adım ortasında kadar olan değerlerinin ortalamasidir.

10. Son Yarı Ortalaması (sonOrt): İvmelenme sinyal genliğinin adım ortasından adım sonuna kadar olan değerlerinin ortalamasidir.

11. Medyan (Med): İvmelenme sinyali genliğinin medyanıdır.

12. Standart Sapma (ss): İvmelenme sinyali genliğinin standart sapmasidir.

13. Çarpıklık (Skew): Ortalama etrafındaki dağılımın asimetri derecesini karakterize eder. $\mathrm{x}$ ivmelenme sinyali, $\mu$ ivmelenme sinyali ortalamasi ve $\sigma$ ivmelenme sinyali standart sapması ve E beklenen değer olmak üzere aşağıdaki şekilde hesaplanır.

$$
\text { Çarpıklık }=\frac{E(x-\mu)^{3}}{\sigma^{3}}
$$

14. Basıklık (Kurt): Ortalama etrafındaki dağılımın diklik ve düzlük derecesini karakterize eder.

$$
\text { Basıklık }=\frac{E(x-\mu)^{4}}{\sigma^{4}}
$$

15. Varyans (Var): İvmelenme sinyali genliğinin varyansıdır.

16. Merkezi Moment (3. Derece) (mom3): İvmelenme sinyali genliğinin üçüncü derece merkezi momentidir.

17. Merkezi Moment (4. Derece) (mom4): İvmelenme sinyali genliğinin dördüncü derece merkezi momentidir. $\mathrm{x}$ ivmelenme sinyali, $\mu$ ivmelenme sinyali ortalaması, $\mathrm{E}$ beklenen değer ve $\mathrm{k}$ derece olmak üzere aşağıdaki şekilde hesaplanır.

$$
m o m k=E(x-\mu)^{k}
$$

18. Çeyrekler Arası Aralık (iqr): İvmelenme sinyali genliğinin ortasını kapsayan ve üçüncü dörtte birlik ve birinci dörtte birlik aralığın farkıdır.

19. Ortalama Mutlak Sapma (oms): İvmelenme sinyalinin her bir değeri ile aritmetik ortalaması arasındaki farkların ortalamasidir.

20. Karekök Ortalama (rms): İvmelenme sinyalinin etkin değeridir.

21. Sinyal Genlik Alanı (sma): Ortalaması çıkarılmış ivmelenme sinyalinin altında kalan alandır.

22. Shanon Entropi (ShanEnp): Shannon entropisi rastgele bir sürecin belirsizliğinin bir ölçüsüdür (Diego Galar 2017). x ivmelenme sinyali, i zaman indisi olmak üzere aşağıdaki şekilde hesaplanır.

$$
\operatorname{ShanEnp}(x)=-\sum_{i} x_{i}^{2} \log \left(x_{i}{ }^{2}\right)
$$

23. Sıfır Geçiş (SG): İvmelenme sinyalinin zaman eksenini kestiği noktaların sayıdır.

24. Tepe Sayısı (TepeN): İvmelenme sinyalindeki tepe sayısıdır.

25. Tepe Değerlerin Ortalaması (ortTepe): İvmelenme sinyalindeki tepe değerlerin ortalamasıdır.

26. Birinci ve İkinci Tepe Arasındaki Süre (Tepe12): Birinci ve ikinci tepenin oluştuğu zamanların farkıdır.

27. Dinamik Zaman Atlama Mesafesi(dza): Dinamik zaman atlama (dynamic time warping) zaman serisi sinyallerinin benzerliğini hesaplayan bir algoritmadır. Bu çalışmada ardışık adımlara ait sinyallerin benzerliğinin bir ölçüsü olarak kullanılmıştır. Xsag sağ adım ivmelenme sinyali, Xsol sol adım ivmelenme sinyali, $\mathrm{k}$ zaman indeksi olmak üzere aşağıdaki şekilde hesaplanır.

$$
d z a=\sqrt{\sum_{k=1}^{K}\left(X \operatorname{sag}_{k}-X \operatorname{sol}_{k}\right) *\left(X \operatorname{sag}_{k}-X \operatorname{sol}_{k}\right)}
$$

\section{Araştırma Sonuçları ve Tartışma}

Dikey, mediyolateral ve ön-arka eksenlerden elde edilen toplam 81 özelliğin ortalama ve standart sapma değerleri Tablo 1 'de verilmektedir. Tablo 1'de sütunlar üç kayıt ekseni için üçe, kendi içinde de kontrol ve düşen sınıfları için ikiye bölünmüştür. Her bir satır da elde edilen özellikler yer almaktadır. Herhangi bir özelliğin kontrol grubu ile düşen grubunu ayırmak için kullanılıp kullanılmayacağını anlayabilmek için bağımsız-örneklem t-testi kullanılarak özelliklerin ortalamaları arasında anlamlı bir fark olup olmadığı \%99 güvenirlik seviyesinde karşılaştırılmıştır. Karşılaştırma sonucunda dikey eksenden kayıt edilen ivmelenme sinyalinin standart sapması (ss_V), çarpıklığı (Kurt_V), çeyrekler arası aralığı (iqr_V), ortalama mutlak sapması (oms_V), mediyolateral eksenden kayit edilen ivmelenme sinyalinin harmonik oranı (HR_ML), ön-arka eksenden kayıt edilen ivmelenme sinyalinin adım süresi (AdS_AP), çift adım süresi (cAdS_AP), kadansı (Kdn_AP) ve dinamik zaman atlama mesafesi (dza_AP) özelliklerinin istatistiksel olarak anlamlı farklılık gösterdiği görülmüştür. Tablo 1 'de bu özellikler koyu olarak yazılmıştır. Şekil 1'de bu özelliklere ait sütun grafikleri görülmektedir. Grafikte ilk sütun kontrol ikinci sütun düşen grubunun ortalama ve standart hata değerlerini göstermektedir.

$\mathrm{Bu}$ çalışmada kontrol ve düşen olarak iki gruba ayrılmış yaşlılardan yürüme esnasında kayıt edilen ivmelenme sinyallerine ait zaman domeni özellikleri incelenmiştir. Bu incelemenin amacı herhangi bir zaman domeni özelliğinin yaşlılarda düşme riskini önceden belirlenmesinde kullanılıp kullanılamayacağını belirlemektir. Literatürde bu konuda yapılan çalışmalar sensorün kayıt esnasında yerleştirildiği vücut konumu ve kayıt esnasındaki yapılan aktiviteye göre sınıflandırılabilir. İvmelenme sensörünün baş, üst sırt, göğüs kemiği, omuz, dirsek, bilek, kalça, bel, uyluk, diz, ayak bileği ve ayak gibi konumlara yerleştirildiği görülmektedir. $\mathrm{Bu}$ konumlardan bizim çalışmamızda da kullanılan bel konumu, çalışmaların \%65'inde kullanılmıştır. Bel vücudun ağırlık merkezi olması ve sensörün basit bir kemer aracılığıyla hastayı rahatsız etmeden yerleştirilmesine imkân sağlaması nedeniyle en uygun bölgedir (Howcroft, Kofman ve ark. 2013). Bu yüzden birinci basamak sağlık kuruşlarında kullanımı hedefleyen çalışmamız için bu yerleşim yerinin uygun olduğu düşünülmektedir. Kayıt esnasında aktivite olarak en sik kullanılan yöntem de yine bizim çalışmamızda kullandığımız düz zeminde yürümedir. Bunun yanında zamanlı kalk ve yürü, oturma kalkma geçişi, sol-sağ adım değiştirme testi gibi aktiviteler kullanılmıştır. Yine burada düz zeminde yürüme basit ve objektif bir yöntem olarak kullanılabilir. Literatürde farklı sensör konumu ve farklı aktivite soncunda elde edilen zaman özelliklerinden anlamlı farklılık gösteren toplam 20 özellik olduğu görülmektedir (Howcroft, Kofman ve ark. 2013). Ancak bu özelliklerden 14 tanesi farklı aktivitelerden elde edilmiş özelliklerdir. Bizim çalışmamızla aynı sensör pozisyonu ve aynı aktiviteden (düz zeminde yürüyüş) elde edilmiş 5 özellik yürüyüş hızı, kadans, adım

Tablo 1. Bütün Özelliklerin Ortalama ve Standart Sapma Değerleri 


\begin{tabular}{|c|c|c|c|c|c|c|}
\hline $\begin{array}{r}\text { Kayıt } \\
\text { Ekseni }\end{array}$ & \multicolumn{2}{|c|}{ Dikey Eksen } & \multicolumn{2}{|c|}{ Mediyolateral Eksen } & \multicolumn{2}{|c|}{$\begin{array}{c}\text { Anterior-Posterior } \\
\text { (Ön-Arka) Eksen }\end{array}$} \\
\hline Özellik & $\begin{array}{c}\text { Kontrol } \\
\text { (Ortalama } \\
\pm \text { Std. Sap.) }\end{array}$ & $\begin{array}{c}\text { Düşen } \\
\text { (Ortalama } \\
\pm \text { Std. Sap.) }\end{array}$ & $\begin{array}{c}\text { Kontrol } \\
\text { (Ortalama } \\
\pm \text { Std. Sap.) }\end{array}$ & $\begin{array}{c}\text { Düşen } \\
\text { (Ortalama } \\
\pm \text { Std. Sap.) }\end{array}$ & $\begin{array}{c}\text { Kontrol } \\
\text { (Ortalama } \\
\pm \text { Std. Sap.) }\end{array}$ & $\begin{array}{c}\text { Düşen } \\
\text { (Ortalama } \\
\pm \text { Std. Sap.) }\end{array}$ \\
\hline$A d S$ & $0,53 \pm 0,05$ & $0,55 \pm 0,04$ & $0,5 \pm 0,12$ & $0,52 \pm 0,16$ & $\mathbf{0 , 5 3} \pm \mathbf{0 , 0 4}$ & $0,57 \pm 0,06$ \\
\hline$c A d S$ & $1,06 \pm 0,09$ & $1,11 \pm 0,07$ & $1 \pm 0,24$ & $1,04 \pm 0,33$ & $1,07 \pm 0,09$ & $1,15 \pm 0,12$ \\
\hline$A d D z$ & $0,72 \pm 0,15$ & $0,62 \pm 0,25$ & $-0,02 \pm 0,18$ & $-0,03 \pm 0,22$ & $0,62 \pm 0,21$ & $0,62 \pm 0,24$ \\
\hline$c A d D z$ & $0,63 \pm 0,22$ & $0,53 \pm 0,29$ & $-0,02 \pm 0,22$ & $-0,06 \pm 0,24$ & $0,71 \pm 0,17$ & $0,64 \pm 0,26$ \\
\hline AdSim & $29,15 \pm 80,72$ & $18,58 \pm 45,86$ & $150,16 \pm 51,17$ & $109,37 \pm 56,63$ & $17,96 \pm 43,13$ & $12,62 \pm 25,07$ \\
\hline$K d n$ & $116,44 \pm 10,1$ & $110,91 \pm 8,18$ & $130,85 \pm 29,07$ & $128,25 \pm 32,4$ & $115,63 \pm 9,89$ & $107,75 \pm 10,08$ \\
\hline$H R$ & $0,02 \pm 0$ & $0,01 \pm 0$ & $\mathbf{0 , 0 4} \pm \mathbf{0 , 0 2}$ & $\mathbf{0 , 0 3} \pm \mathbf{0 , 0 1}$ & $0,01 \pm 0$ & $0,01 \pm 0,01$ \\
\hline Ort & $0,17 \pm 0,11$ & $0,21 \pm 0,11$ & $0,08 \pm 0,07$ & $0,1 \pm 0,08$ & $0,21 \pm 0,09$ & $0,17 \pm 0,1$ \\
\hline ilkOrt & $0,08 \pm 0,12$ & $0,11 \pm 0,13$ & $0,08 \pm 0,07$ & $0,1 \pm 0,1$ & $0,37 \pm 0,1$ & $0,34 \pm 0,11$ \\
\hline sonOrt & $0,28 \pm 0,16$ & $0,32 \pm 0,12$ & $0,09 \pm 0,09$ & $0,11 \pm 0,08$ & $0,05 \pm 0,13$ & $0,01 \pm 0,12$ \\
\hline Med & $0,27 \pm 0,16$ & $0,32 \pm 0,17$ & $0,09 \pm 0,1$ & $0,11 \pm 0,11$ & $0,26 \pm 0,12$ & $0,2 \pm 0,15$ \\
\hline$s S$ & $\mathbf{0 , 5 5} \pm \mathbf{0 , 0 4}$ & $\mathbf{0 , 5 2} \pm \mathbf{0 , 0 4}$ & $0,52 \pm 0,05$ & $0,52 \pm 0,04$ & $0,51 \pm 0,03$ & $0,51 \pm 0,03$ \\
\hline Skew & $-0,48 \pm 0,33$ & $-0,65 \pm 0,37$ & $-0,18 \pm 0,28$ & $-0,26 \pm 0,29$ & $-0,57 \pm 0,35$ & $-0,43 \pm 0,36$ \\
\hline Kurt & $2,55 \pm 0,56$ & $2,93 \pm 0,67$ & $2,94 \pm 0,65$ & $3,05 \pm 0,64$ & $3,01 \pm 0,61$ & $2,86 \pm 0,51$ \\
\hline Var & $0,3 \pm 0,04$ & $0,27 \pm 0,04$ & $0,27 \pm 0,04$ & $0,27 \pm 0,04$ & $0,26 \pm 0,03$ & $0,26 \pm 0,03$ \\
\hline mom3 & $-0,07 \pm 0,04$ & $-0,09 \pm 0,05$ & $-0,02 \pm 0,03$ & $-0,02 \pm 0,03$ & $-0,07 \pm 0,04$ & $-0,05 \pm 0,04$ \\
\hline mom4 & $0,21 \pm 0,03$ & $0,21 \pm 0,04$ & $0,2 \pm 0,04$ & $0,21 \pm 0,04$ & $0,19 \pm 0,02$ & $0,19 \pm 0,02$ \\
\hline$i q r$ & $0,82 \pm 0,16$ & $\mathbf{0 , 7} \pm \mathbf{0 , 1 7}$ & $0,7 \pm 0,13$ & $0,7 \pm 0,12$ & $0,64 \pm 0,12$ & $0,69 \pm 0,13$ \\
\hline oms & $0,46 \pm 0,05$ & $0,42 \pm 0,05$ & $0,41 \pm 0,05$ & $0,41 \pm 0,05$ & $0,4 \pm 0,03$ & $0,41 \pm 0,04$ \\
\hline$r m s$ & $0,59 \pm 0,03$ & $0,58 \pm 0,04$ & $0,55 \pm 0,04$ & $0,56 \pm 0,04$ & $0,56 \pm 0,03$ & $0,56 \pm 0,03$ \\
\hline sma & $1,04 \pm 0,1$ & $1,04 \pm 0,12$ & $0,84 \pm 0,05$ & $0,85 \pm 0,05$ & $1,07 \pm 0,08$ & $1,02 \pm 0,11$ \\
\hline ShanEnp & $11,77 \pm 1,21$ & $12,51 \pm 1,73$ & $9,74 \pm 2,41$ & $10,36 \pm 3,28$ & $10,81 \pm 1,23$ & $11,59 \pm 1,51$ \\
\hline$S G$ & $2,9 \pm 0,54$ & $2,9 \pm 0,57$ & $4,4 \pm 1,57$ & $3,83 \pm 1,35$ & $3,15 \pm 0,52$ & $3,32 \pm 0,46$ \\
\hline TepeN & $3,69 \pm 0,56$ & $3,87 \pm 0,44$ & $3,39 \pm 1,16$ & $3,46 \pm 1,24$ & $3,56 \pm 0,51$ & $3,73 \pm 0,52$ \\
\hline ortTepe & $0,59 \pm 0,1$ & $0,61 \pm 0,1$ & $0,63 \pm 0,09$ & $0,61 \pm 0,11$ & $0,56 \pm 0,1$ & $0,53 \pm 0,1$ \\
\hline Tepe12 & $0,15 \pm 0,03$ & $0,15 \pm 0,02$ & $0,12 \pm 0,02$ & $0,13 \pm 0,03$ & $0,14 \pm 0,03$ & $0,13 \pm 0,03$ \\
\hline$d z a$ & $6,75 \pm 1,6$ & $7,87 \pm 2,1$ & $12,24 \pm 2,73$ & $12,31 \pm 3,23$ & $5,42 \pm 1,57$ & $7,08 \pm 2,75$ \\
\hline
\end{tabular}

süresinin standart sapması, çift adım süresi, çift adım süresi standart sapmasıdır. Kadans, adım süresi, çift adım süresi özellikleri benzer şekilde bizim çalışmamızda da kontrol ile düşen grupları arasında anlamlı fark göstermiştir. Bu özelliklere ilave olarak literatürde daha önce kullanılan ama gruplar arasında anlamlı fark göstermeyen ss_V ve HR_ML özellikleri, bizim çalışmamızda iki grup arasında istatitstiksel olarak anlamlı bir fark göstermiştir. Ayrıca literatürde daha önce düşme riskinin değerlendirilmesi için yapılan çalışmalarda kullanılmayan, çalışmamızda incelediğimiz özellikler arasından Kurt_V, iqr_V, oms_V ve dza_AP özelliklerinin de iki grup arasında anlamlı fark ortaya koyduğu görülmüştür.

Anlamlı farklılık gösteren özellikler çoğunlukla dikey ve önarka eksende kayıt edilen ivmelenme sinyallerinden elde edildiği görülmektedir. Bunun sebebinin mediyolateral eksenden elde edilen kayıtların normal adım harmonisinin dışında salınımlara sahip olması olduğu düşünülmektedir. Bu yüzden adım süresi kestirimleri ve sinyalin parçalara ayrılmasında hatalı sonuçlar verebilmektedir. Tablo 1'de mediyolateral eksenden elde edilen kadans ve adım simetrisi özellikleri incelendiğinde bu durumun etkisi olarak hatalı sonuçlar verdiği görülmektedir. Bu yüzden HR_ML özelliğinin gösterdiği anlamlı farkınğın tekrar değerlendirilmesi gerektiği düşünülmektedir. Çalışmamızda anlamlı farklılık gösteren özelliklerin t-test $\mathrm{p}$ değerleri sıralı olarak Tablo 2'de verilmiştir. Buna göre iki grup arasında en iyi ayrımı gösteren özellikler Kdn-AP, iqr-V, AdS-AP, dza-AP, cAdsAP, oms-V, HR-ML, Kurt-V, ss-V şeklinde sıralanmıştır.

Tablo 2. Bă̆ımsız-örneklem t-testi p değerleri

\begin{tabular}{c|c|c|c|c|c|c|c|c|c}
\hline Özellik & $K d n-A P$ & $i q r-V$ & $A d S-A P$ & $c A d S-A P$ & $d z a-A P$ & $o m s-V$ & $H R-M L$ & $K u r t-V$ & $s s-V$ \\
\hline p-değeri & 0,001 & 0,0015 & 0,002 & 0,002 & 0,002 & 0,005 & 0,008 & 0,0086 & 0,01 \\
\hline
\end{tabular}



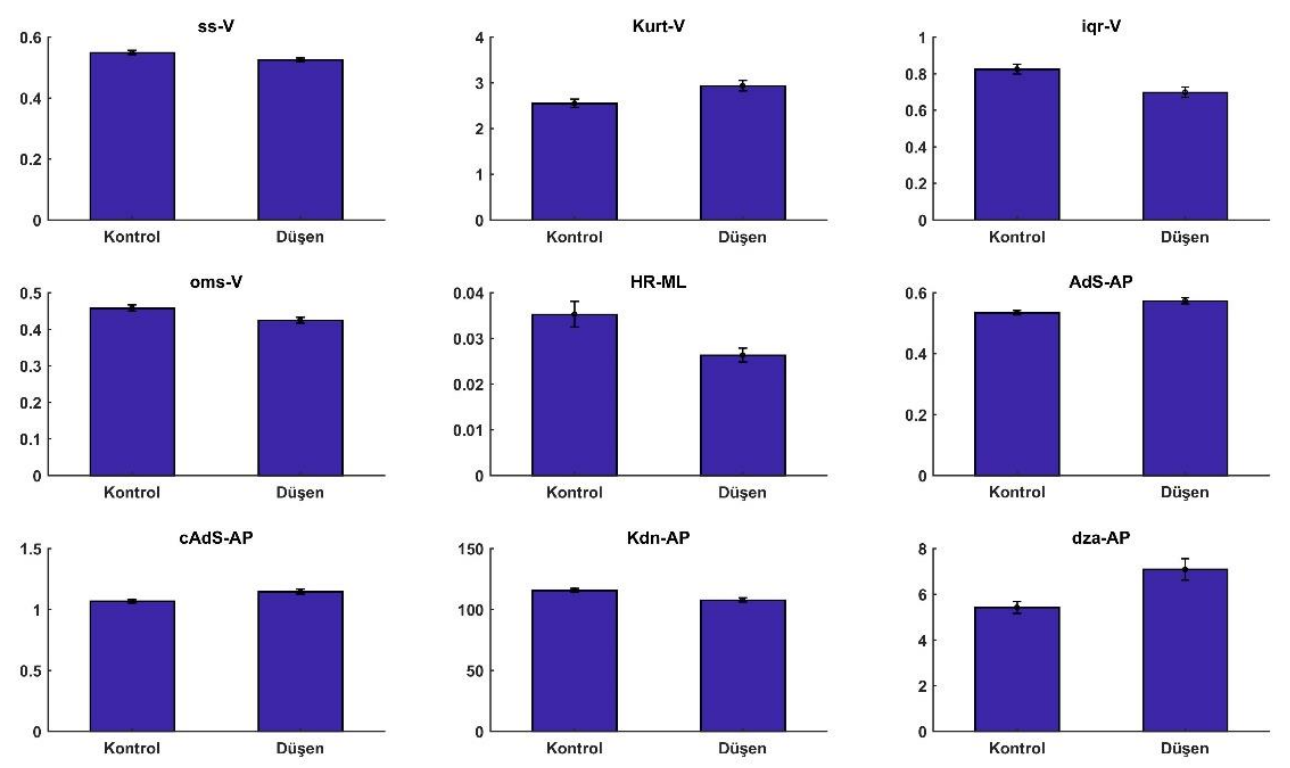

Şekil 1. İstatistiksel olarak anlaml farklılı̆̆a sahip özelliklerin sütun grafikleri

\section{Sonuç}

Fiziksel, psikolojik ve ekonomik etkileri oldukça ciddi olan yaşlılarda düşmenin önlenmesi hem toplum hem bireylerin yaşam kalitesinin artırılması anlamında oldukça önemlidir. Önleme çalışmasının ilk adımı ise sık sık yaşlıların düşme riskinin değerlendirilmesi, ikinci adımı ise uygun değerlendirme yönteminin bulunmasıdır. Düşme riskinin sık değerlendirilmesi ancak birinci basamak sağlık kuruluşlarında gerçekleştirilebilir. Bu yüzden birinci basamak sağlık kuruluşlarında uygulanabilecek basit ve ucuz bir düşme değerlendirme yönteminin geliştirilmesi gerekmektedir. Çalışmamızda ivmelenme sinyallerinden elde edilebilecek bütün zaman domeni özellikleri düşme riskinin belirlenmesi için toplu olarak değerlendirilmiştir. Sonuç olarak literatürde kullanılan zaman domeni özelliklerin yanında, daha önce düşme riski için kullanılmayan dört yeni zaman domeni özelliğinin düşme riskini belirlemede kullanılabilceği görülmüştür. Daha sonraki çalışmalarda farklı domenlerde elde edilen özelliklerin değerlendirilmesi ve bulunan özelliklerin sınıfla performanslarının incelenmesi planlanmaktadır.

\section{Kaynakça}

Balaban, Ö., Nacır, B., Erdem, H. R., \& Karagöz, A. (2009). Denge Fonksiyonunun Dederlendirilmesi. Journal of Physical Medicine and Rehabilitation Sciences, 12(9), 133139.

Barden, J. M., Clermont, C. A., Kobsar, D., \& Beauchet, O. (2016). Accelerometer-Based Step Regularity Is Lower in Older Adults with Bilateral Knee Osteoarthritis. Frontiers in Human Neuroscience, 10 doi:ARTN 62510.3389/fnhum.2016.00625

Bellanca, J. L., Lowry, K. A., VanSwearingen, J. M., Brach, J. S., \& Redfern, M. S. (2013). Harmonic ratios: A quantification of step to step symmetry. Journal of Biomechanics, 46(4), 828-831. Retrieved from $<\mathrm{Go}$ to ISI $>$ ://WOS:000315973700029

Castellini, G., Gianola, S., Stucovitz, E., Tramacere, I., Banfi, G., \& Moja, L. (2019). Diagnostic test accuracy of an automated device as a screening tool for fall risk assessment in community-residing elderly: A STARD compliant study.
Medicine (Baltimore), 98(39), doi:10.1097/MD.0000000000017105

Diego Galar, U. K. (2017). eMaintenance (U. K. Diego Galar Ed.): Academic Press.

Goldberger, A. L., Amaral, L. A., Glass, L., Hausdorff, J. M., Ivanov, P. C., Mark, R. G., . . . Stanley, H. E. (2000). PhysioBank, PhysioToolkit, and PhysioNet: components of a new research resource for complex physiologic signals. Circulation, 101(23), doi:10.1161/01.cir.101.23.e215

Howcroft, J., Kofman, J., \& Lemaire, E. D. (2013). Review of fall risk assessment in geriatric populations using inertial sensors. Journal of Neuroengineering and Rehabilitation, 10. doi:Artn 9110.1186/1743-0003-10-91

Howcroft, J., Kofman, J., \& Lemaire, E. D. (2017a). Feature selection for elderly faller classification based on wearable sensors. Journal of Neuroengineering and Rehabilitation, 14. doi:ARTN 4710.1186/s12984-017-0255-9

Howcroft, J., Kofman, J., \& Lemaire, E. D. (2017b). Prospective Fall-Risk Prediction Models for Older Adults Based on Wearable Sensors. Ieee Transactions on Neural Systems and Rehabilitation Engineering, 25(10), 1812-1820. doi:10.1109/Tnsre.2017.2687100

Karantonis, D. M., Narayanan, M. R., Mathie, M., Lovell, N. H., \& Celler, B. G. (2006). Implementation of a real-time human movement classifier using a triaxial accelerometer for ambulatory monitoring. Ieee Transactions on Information Technology in Biomedicine, 10(1), 156-167. doi:10.1109/Titb.2005.856864

Koyuncu, G., Tuna, F., Yavuz, S., Kabayel, D. D., Koyuncu, M., Özdemir, H., \& N., S. (2017). The last station before fracture: Assessment of falling and loss of balance in elderly. Turk $\mathrm{J}$ Phys Med Rehab, 63(1), 9. doi:10.5606/tftrd.2017.90757

Mathie, M. J., Coster, A. C. F., Lovell, N. H., \& Celler, B. G. (2004). Accelerometry: providing an integrated, practical method for long-term, ambulatory monitoring of human movement. Physiological Measurement, 25(2), R1-R20. Retrieved from < Go to ISI $>$ ://WOS:000221075000001

Moncada, L. V. V., \& Mire, L. G. (2017). Preventing Falls in Older Persons. American Family Physician, 96(4), 240-247. Retrieved https://www.ncbi.nlm.nih.gov/pubmed/28925664 
Najafi, B., Aminian, K., Loew, F., Blanc, Y., \& Robert, P. A. (2002). Measurement of stand-sit and sit-stand transitions using a miniature gyroscope and its application in fall risk evaluation in the elderly. Ieee Transactions on Biomedical Engineering, $49(8)$ 843-851. doi:10.1109/Tbme.2002.800763

Pires IM, G. N., Pombo N, Flórez-Revuelta F, Spinsante S, Canavarro Teixeira M, Zdravevski E. . (2019). Pattern Recognition Techniques for the Identification of Activities of Daily Living using Mobile Device Accelerometer. PeerJ Preprints, doi:https://doi.org/10.7287/peerj.preprints.27225v2

Sun, T. L., \& Huang, C. H. (2019). Interactive visualization to assist fall-risk assessment of community-dwelling elderly people. Information Visualization, 18(1), 33-44. doi:10.1177/1473871617721243

Weiss, A., Brozgol, M., Dorfman, M., Herman, T., Shema, S., Giladi, N., \& Hausdorff, J. M. (2013). Does the evaluation of gait quality during daily life provide insight into fall risk? A novel approach using 3-day accelerometer recordings. Neurorehabil Neural Repair, 27(8), 742-752. doi:10.1177/1545968313491004

WHO. (2007). WHO Global Report on Falls Prevention in Older Age. France: WHO Press.

Wu, C. H., Lee, C. H., Jiang, B. C., \& Sun, T. L. (2019). Multiscale Entropy Analysis of Postural Stability for Estimating Fall Risk via Domain Knowledge of Timed-UpAnd-Go Accelerometer Data for Elderly People Living in a Community. Entropy, 21(11). doi:ARTN 107610.3390/e21111076

Yang, C. C., \& Hsu, Y. L. (2010). A review of accelerometrybased wearable motion detectors for physical activity monitoring. Sensors (Basel), 10(8), 7772-7788. doi:10.3390/s100807772 